\title{
Relation between cognitive impairment and treatment adherence in elderly hypertensive patients
}

This article was published in the following Dove Press journal:

Clinical Interventions in Aging

\author{
Anna Chudiak' \\ Izabella Uchmanowicz' \\ Grzegorz Mazur ${ }^{2}$ \\ 'Department of Clinical Nursing, \\ Faculty of Health Sciences, Wroclaw \\ Medical University, Wrocław, Poland; \\ ${ }^{2}$ Department and Clinic of Internal \\ and Occupational Diseases and \\ Hypertension, Wroclaw Medical \\ University, Wrocław, Poland
}

Background: Nonadherence to medical treatment and lack of cooperation in hypertensive patients $>65$ years of age are believed to be caused by a number of age-related problems, such as cognitive impairment. Numerous epidemiological and prospective studies have demonstrated that hypertension that remains untreated for many years or is unsuccessfully treated for reasons such as poor compliance and adherence of the patient may lead to cognitive impairment.

Objective: The objective of this study was to investigate the occurrence of cognitive impairment and its effect on treatment compliance and adherence in elderly hypertensive patients.

Design: This study was an analytical cross-sectional study.

Patients and methods: The study was conducted on 300 patients aged 65-91 years (mean age $=71.8$ years, $\mathrm{SD}=7.8$ years) diagnosed with hypertension. The following research tools were used: 1) Hill-Bone High Blood Pressure Compliance Scale (HBCS) and 2) MiniMental State Examination (MMSE). We also analyzed medical documentation to obtain basic sociodemographic and clinical data. The study was approved by the Bioethics Committee of the Medical University of Wrocław (no KB-144/2016).

Results: Cognitive impairment occurred in $60 \%$ of the patients. A group of $63 \%$ patients complied with antihypertensive therapy, with the mean score of 20.8 points. Cognitive impairment was strongly correlated with the total score of the HBCS questionnaire $(p<0.001)$ and two of its subscales: "appointment keeping" $(p<0.001)$ and "medication taking" $(p<0.001)$.

Conclusion: Compliance and adherence levels are higher in patients with a higher educational level, whereas male sex adversely affects treatment adherence in elderly hypertensive patients. Keywords: cognitive impairment, compliance, hypertension, old age, treatment adherence

\section{Introduction}

Cognitive functions include a range of intellectual processes such as active memory, language processes (writing, reading and speaking), visual and special processing, abstract thinking and perception of external stimuli. ${ }^{1}$ They enable problem-solving, planning and decision-making. ${ }^{2}$ From the physiological perspective, the aging process results in age-related weakening of the memory and cognitive decline. ${ }^{3}$

Cognitive impairment affects people all around the world. The epidemiological data available confirm the high prevalence of the disease. Currently, dementia disorders occur in 2-10/1,000 people of $\sim 70$ years of age and 20-40 people in the population of 80 -year olds. They are markedly more prevalent in the elderly. ${ }^{4}$

Initial reports on the effect of hypertension on vascular lesions yielded varied results. The relation between chronic high blood pressure and development of vascular lesions was confirmed only after a long-term observation of changes in hypertension 
prior to the occurrence of cognitive impairment. ${ }^{5}$ In the literature on the subject, special attention has been paid to periodic decreases in blood pressure, which may contribute to hypoperfusion of the central nervous system and lead to ischemic changes in elderly subjects. ${ }^{6}$

Numerous epidemiological and prospective studies have demonstrated that hypertension, which remains untreated for many years or is unsuccessfully treated for reasons such as poor compliance and adherence of the patient, may lead to cognitive impairment. ${ }^{7-11}$ It also affects vascular remodeling and atherosclerotic processes, leading to pathological lesions in vessels. Cognitive impairment is most likely caused by ischemia, resulting from changes in microcirculation of the brain. There is no doubt, therefore, that successful antihypertensive therapy lowers the risk of vascular dysfunctions. The association between hypertension and cognitive impairment in the population of elderly patients is currently considered to be scientifically confirmed. ${ }^{12}$

Nonadherence to medical treatment and lack of cooperation in hypertensive patients $>65$ years of age are believed to be caused by a number of age-related problems, such as cognitive impairment. ${ }^{13}$

In the previous studies, it was proved that cognitive impairment may negatively affect the ability of patients to adhere to treatment protocols and medication regimes. ${ }^{14-16}$ A systematic review of medication nonadherence in people with dementia or cognitive impairment by Smith et al showed a poor adherence in people with cognitive impairment ranging from $10.7 \%$ to $38 \%$, whereas adherence levels ranged from $17 \%$ to $100 \%$ among older adults with Alzheimer's disease. The authors emphasized that there are very limited systematic reviews to deconstruct cognitive functioning and identify specific domains associated with medication adherence and related behaviors. ${ }^{17}$

Results from another systematic review by Campbell et $\mathrm{al}^{18}$ identified several barriers to medication adherence in populations with cognitive impairment, such as memory disturbances, medication knowledge, health literacy, concern for adverse effects and cost. Moreover, a disconnection between barriers identified by patients and caregivers and those identified by health-care providers and researchers were indicated.

Austin et a ${ }^{19}$ demonstrated that cognitive function is linked closely to the spread in the timing of taking medications and that patients with poorer cognitive function exhibited a larger increase in this spread over time. In addition, Jerant et $\mathrm{al}^{20}$ in their observational cohort study from 771 patients showed that a lower cognitive function is significantly associated with nonadherence. Johnell ${ }^{21}$ reported that prevalence of nonadherence (named as an inappropriate drug use) in patients with cognitive impairment and dementia ranges from $10.2 \%$ to $56.4 \%$.

Good compliance and perseverance result in better treatment outcomes, lower healthcare costs and increased satisfaction of both the patient and the entire medical team. ${ }^{22}$ Adherence to treatment recommendations and active attitude to prescribed medications may prevent the development of complications and progressing decline of daily functioning within the perspective of several years. ${ }^{23}$ Despite these findings, there is a little knowledge about the relationship between cognitive impairment and adherence to recommended treatment among older adults with hypertension.

Therefore, the purpose of this study was to investigate the occurrence of cognitive impairment and its effect on treatment compliance and adherence in elderly hypertensive patients.

\section{Patients and methods}

\section{Study participants}

This prospective cross-sectional and analytical study involved 300 patients treated in the University Teaching Hospital, Wroclaw, Poland, who were admitted due to aggravated hypertension. All the participants gave their informed consent to participate in the study and were informed of their right to withdraw from it at any time.

\section{Research tools}

The following research tools were used in the study: 1) Hill-Bone High Blood Pressure Compliance Scale (HBCS) and 2) Mini-Mental State Examination (MMSE). We also analyzed medical documentation to obtain basic sociodemographic and clinical data.

\section{High Blood Pressure Compliance Scale}

The HBCS questionnaire is a tool for assessing patient compliance with antihypertensive therapy requirements. The original HBCS consists of 14 four-point Likert-type items ( $1=$ none of the time, $2=$ some of the time, $3=$ most of the time and $4=$ all the time) with three underlying domains: "medication taking", "appointment keeping" and "salt intake". The reduced sodium intake subscale contains three questions (score range: 3-12). The appointment keeping subscale consists of two questions (score range: $2-8$ ). The medication taking subscale contains nine questions (score range: 9-36). The maximum (Max) score to be obtained is 56 points. The higher the number of points, the lower the 
adherence to therapy requirements. For the purpose of the present study, we used the Polish adaptation of the HBCS questionnaire. The Cronbach's alpha score for the entire questionnaire was $0.851 .^{24}$

\section{Mini -Mental State Examination}

The MMSE scale is a tool for measuring cognitive impairment. It consists of 30 questions that examine various aspects of cognitive performance. The test assesses orientation to time, orientation to space, registration, attention, calculation, recall, naming, repetition, comprehension, reading, writing and drawing. The respondent scores 1 point for each correct answer, the Max score being 30. Normal cognition is within the range of $27-30$ points. Cognitive decline without dementia is recognized at 24-26 points. A score of 19-23 points indicates mild impairment, 11-18 points medium impairment and 0-10 points severe impairment. ${ }^{25}$ For the purpose of the present study, we used the Polishlanguage version of the MMSE questionnaire.

\section{Statistical analysis}

The analysis of quantitative variables was conducted by calculating the mean $(M), \mathrm{SD}$, median $(\mathrm{Me})$, quartiles $(Q)$, minimum (Min) and Max values. We have also used the Mann-Whitney $U$ test, Spearman's coefficient and the Shapiro-Wilk test. The analysis of qualitative variables involved calculating the number and percentage of occurrences for each variable. Multivariate analysis was conducted using linear regression. A degree to which the obtained model explained variation in the dependent variable was assessed by calculating the coefficient of determination $\left(R^{2}\right)$. The threshold for statistical significance was set at $p<0.05$. The analysis was conducted in R statistical software, version 3.3.

\section{Ethical considerations}

The study was approved by the Bioethics Committee of the Medical University of Wrocław, Poland (no KB-144/2016). The study was conducted in accordance with the guidelines of the Declaration of Helsinki and the principles of Good Clinical Practice as well as in respect for the rights and dignity of the other person. Signed informed consent forms were obtained from all patients who were included in the study.

\section{Results}

The study involved 300 patients (167 females and 133 males) with diagnosed hypertension. The age ranged between 65 and 91 years $(M=71.8, \mathrm{SD}=7.8)$. The mean value for systolic blood pressure was $142 \mathrm{mmHg}(\mathrm{SD}=18.1 \mathrm{mmHg})$ and that for $\mathrm{DBP}$ was $85 \mathrm{mmHg}(\mathrm{SD}=14.2)$. The mean duration of the disease was 13.7 years ( $\mathrm{SD}=8.5$ years). The sociodemographic and clinical data are shown in Table 1.

In the MMSE questionnaire, 120 out of $300(40 \%)$ participants had a normal score, 76 (25.3\%) patients had moderate impairment, 53 (17.7\%) patients had mild impairment, $41(13.7 \%)$ patients had cognitive impairment without dementia and $10(3.3 \%)$ patients had severe impairment (Figure 1).

The HBCS scores ranged between 14 and 56 points. The higher score indicates the poorer compliance and adherence. The mean score was $20.8(\mathrm{SD}=4.1)$. The total HBCS scores were within the range of 14-34 points. Half of the respondents scored $<20$ points and the other half $>20$ points ( $\mathrm{Me}=20$ points). The largest number of participants scored 18-23 points (first quartile [Q1]=18 points, third quartile [Q3]=23 points). The first subscale - reduced sodium intake consisted of three questions with a score range of 3-12.

Table I Basic sociodemographic and clinical characteristics of the study subjects

\begin{tabular}{|c|c|c|}
\hline Parameters & Mean (SD) & Me (QI-Q3) \\
\hline Age (years) & $71.8(7.8)$ & $68(65-78)$ \\
\hline Systolic blood pressure (mmHg) & $142(18.1)$ & $140(130-150)$ \\
\hline Diastolic blood pressure $(\mathrm{mmHg})$ & $85(14.2)$ & $90(80-90)$ \\
\hline \multirow[t]{2}{*}{ Duration of disease (years) } & I3.7 (8.5) & $12(7-17)$ \\
\hline & $\mathbf{n}$ & $\%$ \\
\hline \multicolumn{3}{|l|}{ Sex } \\
\hline Female & 167 & 55.7 \\
\hline Male & 133 & 44.3 \\
\hline \multicolumn{3}{|l|}{ Comorbidities } \\
\hline Diabetes mellitus & 161 & 53.7 \\
\hline Ischemic heart disease & 86 & 28.7 \\
\hline Kidney failure & 38 & 12.7 \\
\hline Rheumatic disorders & 55 & 18.3 \\
\hline \multicolumn{3}{|l|}{ Marital status } \\
\hline Married/living with a partner & 161 & 53.7 \\
\hline Single & 17 & 5.7 \\
\hline Separated/divorced & 12 & 4 \\
\hline Widowed & 110 & 36.7 \\
\hline \multicolumn{3}{|l|}{ Education } \\
\hline None/elementary & 84 & 28 \\
\hline Medium & 138 & 46 \\
\hline Higher vocational or higher & 78 & 26 \\
\hline \multicolumn{3}{|l|}{ Professional activity } \\
\hline Professional & 47 & 157 \\
\hline Retired & 202 & 67.3 \\
\hline Pensioner & 49 & 16.3 \\
\hline Unemployed & 2 & 0.7 \\
\hline \multicolumn{3}{|l|}{ Type of therapy } \\
\hline Monotherapy & 129 & 43 \\
\hline Polytherapy & I7| & 57 \\
\hline
\end{tabular}

Abbreviations: Me, median; QI, first quartile; Q3, third quartile. 


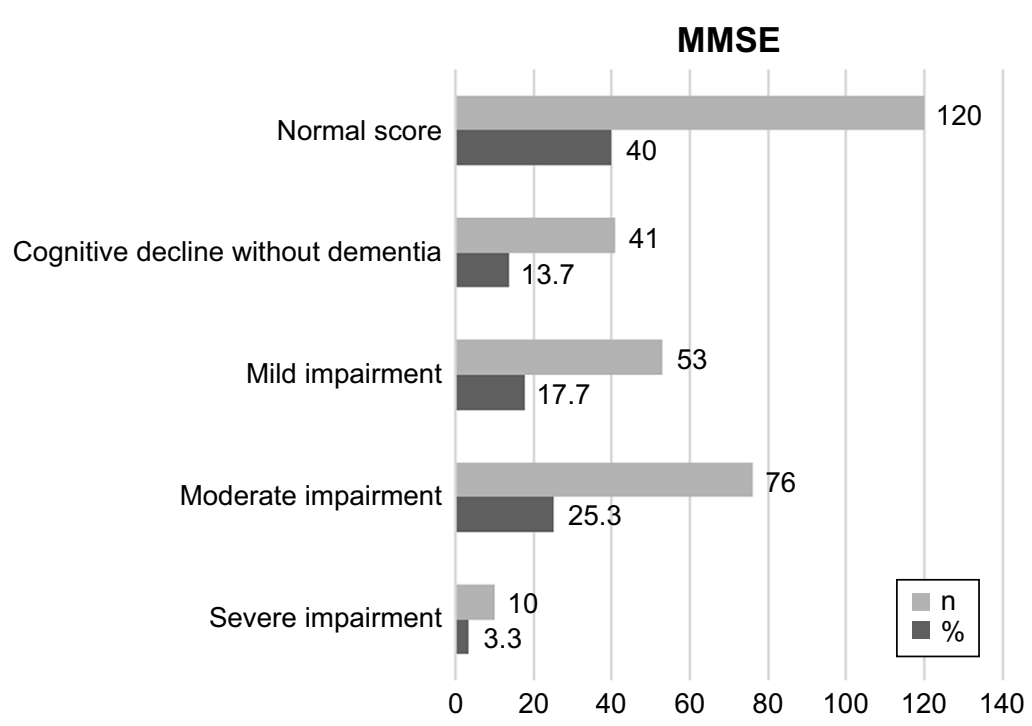

Figure I MMSE questionnaire results.

Abbreviations: MMSE, Mini-Mental State Examination; n, number of participants.

The mean score was $4.8(\mathrm{SD}=1.2)$. The second subscale appointment keeping - consisted of two questions with a score range of 2-8. The mean score in this subscale was 3.5 $(\mathrm{SD}=1.1)$. The last subscale - medication taking - consisted of nine questions with a score range of 9-36. The mean score was 12.5 ( $\mathrm{SD}=3.3$; Figures 2 and 3$)$.

\section{Effect of cognitive impairment on compliance and adherence}

Cognitive impairment significantly affected total scores of the HBCS questionnaire and two of its subscales: appointment keeping and medication taking $(p<0.001)$. These associations were negative, ie, the higher the MMSE score (indicating less severe impairment), the lower the HBCS score (indicating better compliance and adherence; Table 2).

\section{Multivariate analysis}

Within the linear regression model, the total compliance and adherence score measured using the HBCS questionnaire $(p<0.05)$ was influenced by the following variables: 1$)$ sex: compared with female subjects, the mean total HBCS scores of male patients were higher by 1.16 points ( $p=0.01$, $\mathrm{CI}=0.34-1.97)$, which indicates poorer compliance and adherence in this group; 2) education: compared with patients with none or elementary education, the mean total HBCS scores of patients with a higher education were higher by 1.87 points ( $p=0.00, \mathrm{CI}=-3.13$ to -0.62 ), which indicates better compliance and adherence in this group and 3) MMSE score: every additional point in the MMSE questionnaire lowers the mean HBCS total score by 0.19 points $(p<0.001, \mathrm{CI}=-0.29$

\section{HBCS}

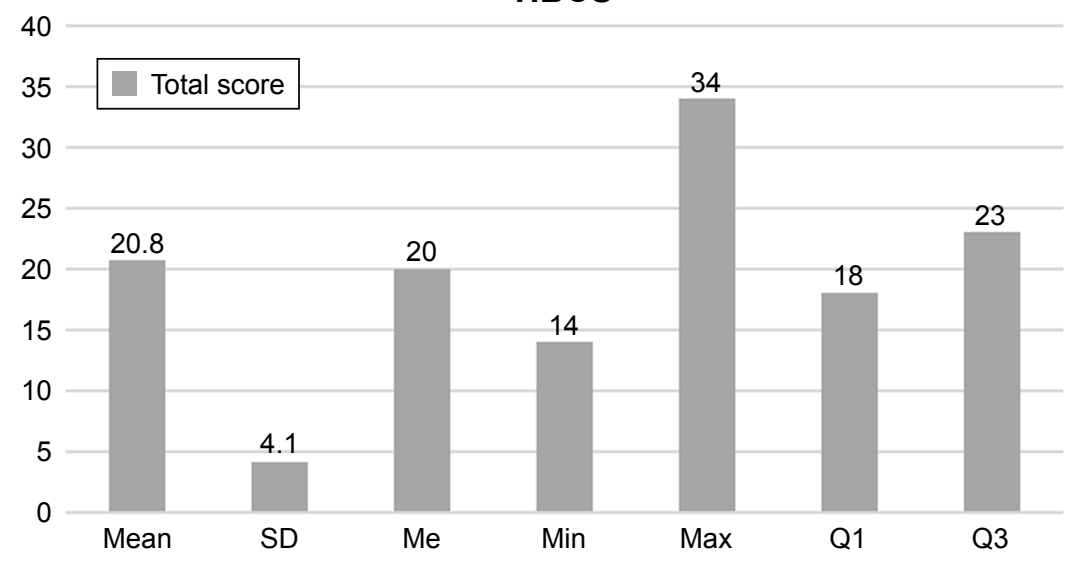

Figure 2 Hill-Bone total score (HBCS).

Abbreviations: HBCS, High Blood Pressure Compliance Scale; Me, median; Min, minimum; Max, maximum; QI, first quartile; Q3, third quartile. 


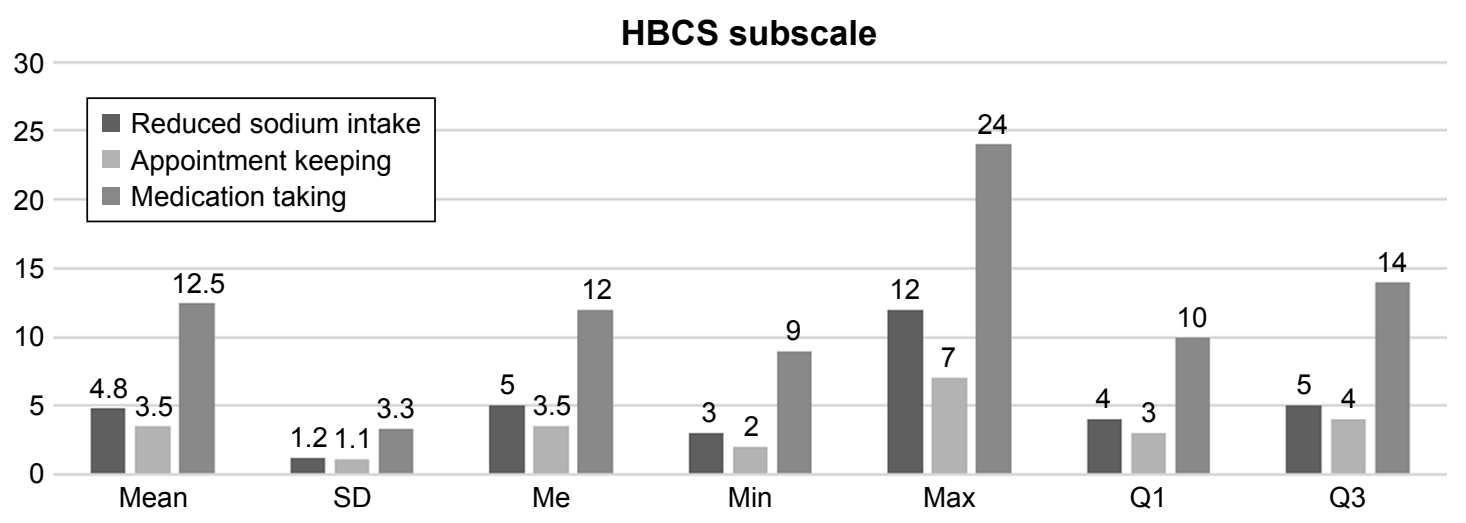

Figure 3 HBCS subscale scores.

Abbreviations: HBCS, High Blood Pressure Compliance Scale; Me, median; Min, minimum; Max, maximum; QI, first quartile; Q3, third quartile.

to -0.09), indicating better compliance and adherence in subjects with no cognitive impairment.

The $R^{2}$ coefficient for this model was $40 \%$, which indicates that $40 \%$ of the HBCS total score variance was explained by the variables used in the model. The remaining $60 \%$ depended on variables that were not included in the model and random factors (Table 3).

\section{Multivariate analysis of the "reduced sodium intake" subscale}

Within the linear regression model, the compliance and adherence HBCS score for the "reduced sodium intake" subscale $(p<0.05)$ was influenced by the following variables: 1) sex: male sex increased the mean score in this subscale by 0.29 points $(p=0.04, \mathrm{CI}=0.01-0.57)$, which indicates poorer compliance and adherence in males; 2) professional activity: retirement increased the mean score in this subscale by 0.57 points ( $p=0.01, \mathrm{CI}=-0.98$ to -0.17 ), which indicates poorer compliance and adherence in people who are not professionally active and 3) diabetes: diabetes increased the mean score in this subscale by 0.36 points $(p=0.02$, $\mathrm{CI}=0.07-0.65)$, which indicates poorer compliance and adherence in patients suffering from the disease.

The $R^{2}$ coefficient for this model was $13.4 \%$, which means that $13.4 \%$ of the HBCS total score variance was explained by the variables used in the model. The remaining $86.6 \%$ depended on variables that were not included in the model and random factors (Table 4).

\section{Multivariate analysis of the appointment keeping subscale}

The linear regression model did not show any significant variables for the scores in the appointment keeping subscale.

The $R^{2}$ coefficient for this model was $23.1 \%$, which means that $23.1 \%$ of the HBCS total score variance was explained by the variables used in the model. The remaining $76.9 \%$ depended on variables that were not included in the model and random factors (Table 5).

\section{Multivariate analysis of the medication taking subscale}

Within the linear regression model, the compliance and adherence HBCS score for the medication taking subscale was influenced by the following variables $(p<0.05)$ : 1$)$ sex: male sex increased the mean score in this subscale by 0.79 points $(p=0.02, \mathrm{CI}=0.15-1.43)$, which indicates poorer compliance and adherence in males; 2) education: mean scores of patients with a higher vocational education or a higher education were lower by 1.58 points $(p=0.00$, $\mathrm{CI}=-2.57$ to -0.59$)$, which indicates better compliance and

Table 2 Effect of cognitive impairment on the quality of life, compliance and adherence

\begin{tabular}{|c|c|c|c|c|}
\hline \multirow[t]{2}{*}{ HBCS subscale } & \multicolumn{4}{|c|}{ Correlation with MMSE } \\
\hline & $\begin{array}{l}\text { Correlation } \\
\text { coefficient }\end{array}$ & $P$-value & $\begin{array}{l}\text { Direction of } \\
\text { correlation }\end{array}$ & $\begin{array}{l}\text { Strength of } \\
\text { correlation }\end{array}$ \\
\hline Total score & -0.5 & $<0.001$ & Negative & Moderate \\
\hline Reduced sodium intake & -0.04 & 0.5 & - & - \\
\hline Appointment keeping & -0.3 & $<0.001$ & Negative & Weak \\
\hline Medication taking & -0.5 & $<0.001$ & Negative & Moderate \\
\hline
\end{tabular}

Abbreviations: HBCS, High Blood Pressure Compliance Scale; MMSE, Mini-Mental State Examination. 
Table 3 Multivariate analysis of the HBCS total score

\begin{tabular}{|c|c|c|c|}
\hline Variables & Parameter & $p$-value & $\mathbf{C l}$ \\
\hline \multicolumn{4}{|l|}{ Sex } \\
\hline \multicolumn{4}{|l|}{ Female - ref. item } \\
\hline Male & 1.16 & 0.01 & $0.34-1.97$ \\
\hline Age (years) & -0.03 & 0.6 & $-0.13-0.07$ \\
\hline \multicolumn{4}{|l|}{ Marital status } \\
\hline \multicolumn{4}{|l|}{ Married/living with } \\
\hline \multicolumn{4}{|l|}{ partner - ref. item } \\
\hline Single/separated/divorced & 1.31 & 0.08 & $-0.14-2.76$ \\
\hline Widowed & 0.59 & 0.33 & $-0.59-1.77$ \\
\hline \multicolumn{4}{|l|}{ Education } \\
\hline \multicolumn{4}{|l|}{$\begin{array}{l}\text { None or elementary - ref. } \\
\text { item }\end{array}$} \\
\hline Medium & -0.79 & 0.16 & $-1.88-0.3$ \\
\hline Higher vocational or higher & -1.87 & 0.00 & -3.13 to -0.62 \\
\hline \multicolumn{4}{|l|}{ Professional activity } \\
\hline \multicolumn{4}{|l|}{ Professional - ref. item } \\
\hline Retired & -1.18 & 0.05 & $-2.36-0$ \\
\hline Pensioner/unemployed & -1.25 & 0.1 & $-2.73-0.23$ \\
\hline Duration of disease (years) & -0.04 & 0.19 & $-0.09-0.02$ \\
\hline \multicolumn{4}{|l|}{ Diabetes mellitus } \\
\hline \multicolumn{4}{|l|}{ No - ref. item } \\
\hline Yes & 0.66 & 0.13 & $-0.18-1.5$ \\
\hline \multicolumn{4}{|l|}{ Ischemic heart disease } \\
\hline \multicolumn{4}{|l|}{ No - ref. item } \\
\hline Yes & 0.5 & 0.31 & $-0.46-1.45$ \\
\hline \multicolumn{4}{|l|}{ Kidney failure } \\
\hline \multicolumn{4}{|l|}{ No - ref. item } \\
\hline Yes & -0.12 & 0.85 & $-1.33-1.1$ \\
\hline \multicolumn{4}{|l|}{ Rheumatic disorders } \\
\hline \multicolumn{4}{|l|}{ No - ref. item } \\
\hline Yes & 0.36 & 0.5 & $-0.67-1.39$ \\
\hline \multicolumn{4}{|l|}{ Therapy } \\
\hline \multicolumn{4}{|l|}{ Monotherapy - ref. item } \\
\hline Polytherapy & 0.31 & 0.65 & $-1.04-1.67$ \\
\hline MMSE (points) & -0.19 & $<0.001$ & -0.29 to -0.09 \\
\hline
\end{tabular}

Abbreviations: HBCS, High Blood Pressure Compliance Scale; ref., reference; MMSE, Mini-Mental State Examination.

adherence in this group and 3) MMSE score. Every additional point in the MMSE questionnaire lowered the mean score in this subscale by 0.15 points $(p<0.001, \mathrm{CI}=-0.23$ to -0.07$)$, indicating better compliance and adherence in subjects with no cognitive impairment.

The $R^{2}$ coefficient for this model was $41.5 \%$, which means that $41.5 \%$ of the HBCS total score variance was explained by the variables used in the model. The remaining $58.5 \%$ depended on variables that were not included in the model and random factors (Table 6).

\section{Discussion}

Nonadherence to therapy and lack of cooperation during treatment are crucial issues to be considered in elderly patients.
Table 4 Multivariate analysis of the "reduced sodium intake" subscale

\begin{tabular}{|c|c|c|c|}
\hline Variables & Parameter & $p$-value & Cl \\
\hline \multicolumn{4}{|l|}{ Sex } \\
\hline \multicolumn{4}{|l|}{ Female - ref. item } \\
\hline Male & 0.29 & 0.04 & $0.0 \mathrm{I}-0.57$ \\
\hline Age (years) & 0.01 & 0.59 & $-0.02-0.04$ \\
\hline \multicolumn{4}{|l|}{ Marital status } \\
\hline \multicolumn{4}{|l|}{ partner - ref. item } \\
\hline Single/separated/divorced & 0.37 & 0.15 & $-0.13-0.86$ \\
\hline Widowed & 0.30 & 0.14 & $-0.1-0.7 \mid$ \\
\hline \multicolumn{4}{|l|}{ Education } \\
\hline \multicolumn{4}{|l|}{$\begin{array}{l}\text { No or elementary - ref. } \\
\text { item }\end{array}$} \\
\hline Medium & -0.12 & 0.54 & $-0.49-0.26$ \\
\hline Higher vocational or higher & -0.11 & 0.63 & $-0.54-0.32$ \\
\hline \multicolumn{4}{|c|}{ Professional activity } \\
\hline \multicolumn{4}{|l|}{ Professional - ref. item } \\
\hline Retired & -0.57 & 0.01 & -0.98 to -0.17 \\
\hline Pensioner/unemployed & -0.33 & 0.2 & $-0.84-0.18$ \\
\hline Duration of disease (years) & -0.01 & 0.28 & $-0.03-0.01$ \\
\hline \multicolumn{4}{|l|}{ Diabetes mellitus } \\
\hline \multicolumn{4}{|l|}{ No - ref. item } \\
\hline Yes & 0.36 & 0.02 & $0.07-0.65$ \\
\hline \multicolumn{4}{|l|}{ Ischemic heart disease } \\
\hline \multicolumn{4}{|l|}{ No - ref. item } \\
\hline Yes & 0.18 & 0.28 & $-0.15-0.5 \mid$ \\
\hline \multicolumn{4}{|l|}{ Kidney failure } \\
\hline \multicolumn{4}{|l|}{ No - ref. item } \\
\hline Yes & -0.06 & 0.76 & $-0.48-0.35$ \\
\hline \multicolumn{4}{|l|}{ Rheumatic disorders } \\
\hline \multicolumn{4}{|l|}{ No - ref. item } \\
\hline Yes & 0.01 & 0.94 & $-0.34-0.37$ \\
\hline \multicolumn{4}{|l|}{ Type of therapy } \\
\hline \multicolumn{4}{|l|}{ Monotherapy - ref. item } \\
\hline Polytherapy & -0.03 & 0.92 & $-0.49-0.44$ \\
\hline MMSE (points) & -0.01 & 0.6 & $-0.05-0.03$ \\
\hline
\end{tabular}

Abbreviations: ref., reference; MMSE, Mini-Mental State Examination.

The reasons behind this worrying phenomenon include psychological aspects, beliefs about health, anxiety and depression symptoms and age-related disorders. Compliance with medical treatment and good patient cooperation are the key to an effective antihypertensive therapy. Detecting the source of the problem appears extremely important for implementing appropriate strategies aiming to improve adherence and compliance.

In our study, cognitive impairment occurred in $60 \%$ of the patients: $25.3 \%$ of patients had moderate impairment; $17.7 \%$ had mild impairment; $13.7 \%$ had cognitive decline without dementia and $3.3 \%$ had a severe impairment. Another important factor in this group of patients is concomitant hypertension, which contributes to vessel lesions. Therefore, 
Table 5 Multivariate analysis of the appointment keeping subscale

\begin{tabular}{|c|c|c|c|}
\hline Variables & Parameter & $p$-value & $\mathrm{Cl}$ \\
\hline \multicolumn{4}{|l|}{ Sex } \\
\hline \multicolumn{4}{|l|}{ Female - ref. item } \\
\hline Male & 0.08 & 0.54 & $-0.17-0.32$ \\
\hline Age (years) & -0.01 & 0.51 & $-0.04-0.02$ \\
\hline \multicolumn{4}{|l|}{ Marital status } \\
\hline \multicolumn{4}{|l|}{$\begin{array}{l}\text { Married/living with partner - } \\
\text { ref. item }\end{array}$} \\
\hline Single/separated/divorced & 0.22 & 0.32 & $-0.21-0.65$ \\
\hline Widowed & 0.3 & 0.10 & $-0.06-0.65$ \\
\hline \multicolumn{4}{|l|}{ Education } \\
\hline \multicolumn{4}{|l|}{ None or elementary - ref. item } \\
\hline Medium & 0.19 & 0.25 & $-0.13-0.52$ \\
\hline Higher vocational or higher & -0.19 & 0.33 & $-0.56-0.19$ \\
\hline \multicolumn{4}{|l|}{ Professional activity } \\
\hline \multicolumn{4}{|l|}{ Professional - ref. item } \\
\hline Retired & 0.05 & 0.77 & $-0.3-0.4$ \\
\hline Pensioner/unemployed & -0.04 & 0.87 & $-0.48-0.41$ \\
\hline History of the disease (years) & -0.01 & 0.38 & $-0.0-0.01$ \\
\hline \multicolumn{4}{|l|}{ Diabetes mellitus } \\
\hline \multicolumn{4}{|l|}{ No - ref. item } \\
\hline Yes & 0.13 & 0.3 & $-0.12-0.39$ \\
\hline \multicolumn{4}{|l|}{ Ischemic heart disease } \\
\hline \multicolumn{4}{|l|}{ No - ref. item } \\
\hline Yes & 0.16 & 0.27 & $-0.12-0.45$ \\
\hline \multicolumn{4}{|l|}{ Kidney failure } \\
\hline \multicolumn{4}{|l|}{ No - ref. item } \\
\hline Yes & 0.06 & 0.75 & $-0.3-0.42$ \\
\hline \multicolumn{4}{|l|}{ Rheumatic disorders } \\
\hline \multicolumn{4}{|l|}{ No - ref. item } \\
\hline Yes & -0.00 & 0.98 & $-0.3 \mid-0.3$ \\
\hline \multicolumn{4}{|l|}{ Type of therapy } \\
\hline \multicolumn{4}{|l|}{ Monotherapy - ref. item } \\
\hline Polytherapy & 0.38 & 0.07 & $-0.03-0.78$ \\
\hline MMSE (points) & -0.03 & 0.06 & $-0.06-0$ \\
\hline
\end{tabular}

Abbreviations: ref., reference; MMSE, Mini-Mental State Examination.

research in this area may have interesting practical implications. In this context, it is worth mentioning about Kilander et $\mathrm{al}^{5}$ and Skoog et $\mathrm{al}^{26}$ who reported a significantly stronger correlation in patients who did not take hypotensive medication in comparison with pharmacologically treated patients with cognitive impairment.

Another study, 20-year follow-up by Elias et al, ${ }^{12}$ demonstrated that high blood pressure adversely affected memory and concentration in the group of elderly patients. Tzourio et $\mathrm{al}^{27}$ observed an approximately threefold increase in the prevalence of cognitive decline in a population of hypertensive patients in comparison with healthy individuals. Moreover, a longitudinal study (2 and 4 years) of hypertensive patients confirmed a higher risk of cognitive
Table 6 Multivariate analysis of the "medication taking" subscale

\begin{tabular}{|c|c|c|c|}
\hline Variables & Parameter & $p$-value & $\mathrm{Cl}$ \\
\hline \multicolumn{4}{|l|}{ Sex } \\
\hline \multicolumn{4}{|l|}{ Female - ref. item } \\
\hline Male & 0.79 & 0.02 & $0.15-1.43$ \\
\hline Age (years) & -0.03 & 0.48 & $-0.1-0.05$ \\
\hline \multicolumn{4}{|l|}{ Marital status } \\
\hline \multicolumn{4}{|l|}{ Married/living with } \\
\hline \multicolumn{4}{|l|}{ partner - ref. item } \\
\hline Single/separated/divorced & 0.72 & 0.22 & $-0.43-1.87$ \\
\hline Widowed & -0.01 & 0.99 & $-0.94-0.93$ \\
\hline \multicolumn{4}{|l|}{ Education } \\
\hline \multicolumn{4}{|l|}{$\begin{array}{l}\text { None or elementary - ref. } \\
\text { item }\end{array}$} \\
\hline Medium & -0.87 & 0.05 & $-1.73-0$ \\
\hline Higher vocational or higher & -1.58 & 0.00 & -2.57 to -0.59 \\
\hline \multicolumn{4}{|l|}{ Professional activity } \\
\hline \multicolumn{4}{|l|}{ Professional - ref. item } \\
\hline Retired & -0.66 & 0.17 & $-1.59-0.27$ \\
\hline Pensioner/unemployed & -0.88 & 0.14 & $-2.06-0.3$ \\
\hline History of the disease (years) & -0.02 & 0.39 & $-0.06-0.02$ \\
\hline \multicolumn{4}{|l|}{ Diabetes mellitus } \\
\hline \multicolumn{4}{|l|}{ No - ref. item } \\
\hline Yes & 0.17 & 0.63 & $-0.5-0.83$ \\
\hline \multicolumn{4}{|l|}{ Ischemic heart disease } \\
\hline \multicolumn{4}{|l|}{ No - ref. item } \\
\hline Yes & 0.15 & 0.7 & $-0.6|-0.9|$ \\
\hline \multicolumn{4}{|l|}{ Kidney failure } \\
\hline \multicolumn{4}{|l|}{ No - ref. item } \\
\hline Yes & -0.11 & 0.82 & $-1.07-0.85$ \\
\hline \multicolumn{4}{|l|}{ Rheumatic disorders } \\
\hline \multicolumn{4}{|l|}{ No - ref. item } \\
\hline Yes & 0.35 & 0.4 & $-0.46-1.16$ \\
\hline \multicolumn{4}{|l|}{ Type of therapy } \\
\hline \multicolumn{4}{|l|}{ Monotherapy - ref. item } \\
\hline Polytherapy & -0.04 & 0.94 & $-1.11-1.03$ \\
\hline MMSE (points) & -0.15 & $<0.001$ & -0.23 to -0.07 \\
\hline
\end{tabular}

Abbreviations: ref., reference; MMSE, Mini-Mental State Examination.

impairment in untreated hypertensive patients compared to those successfully treated. ${ }^{27}$

Interesting results were also obtained by Launer et $\mathrm{al}^{28}$ who demonstrated that the risk for cognitive function impairment increased by $7 \%$ for every $10 \mathrm{mmHg}$ increase in systolic blood pressure. Hanon ${ }^{29}$ demonstrated that hypertension is one of the key risk factors of cardiovascular diseases and is strongly correlated with cognitive decline and dementia. Moreover, data from recent trials (SYST-EUR, PROGRESS, HOPE, SCOPE and HYVET) emphasize that prevention of cognitive decline should involve appropriate antihypertensive treatment. For this reason, the effect of antihypertensive treatment on cognitive functions is one of the main trends in the current research on elderly hypertensive patients. ${ }^{29,30}$ 
As regards compliance with treatment requirements, the mean score in our study was 20.8 points out of 56 . The range of scores was 14-34. This indicates compliance and adherence of $63 \%$ of the subjects. Higher results indicated worse compliance and adherence to therapy. In the study by Ramli et al, ${ }^{31}$ the appropriate level of adherence and compliance was observed in $53 \%$ of 653 hypertensive patients with a mean age of 57.8 years. Among the factors that adversely affect compliance and adherence enumerated by the authors were poor knowledge of the medications and the purpose of taking them and lack of knowledge on comorbidities and polypragmasy.

The study by Osamor and Owumi ${ }^{32}$ on 440 hypertensive patients with a mean age of 60 years found a high compliance and adherence level in $51 \%$ of the subjects. The patients gave the following reasons for missing or not taking antihypertensive medications: feeling better (11\%), forgetfulness $(8 \%)$, lack of funds (7\%) and side effects of the medications (6\%). Another study confirmed that only one-third of the respondents were aware that antihypertensive medications should be taken for life regardless of symptoms or blood pressure. In this study, as many as $58.3 \%$ of the subjects believed that pharmacotherapy should be applied only when symptoms of hypertension occur. ${ }^{33}$

With regard to the relation between sex and compliance/ adherence levels, males showed a significantly lower compliance and adherence than females. Some other studies ${ }^{34,35}$ reported that females were more compliant and adherent to therapy, as well as they were also less likely to stop pharmacotherapy. However, Gokdemir et al ${ }^{16}$ obtained contradictory results and did not find a relation between sex and compliance or adherence levels.

Our analysis has shown that higher education improves compliance and adherence compared with elementary or no education. Previous studies confirmed that people with a higher educational level may show better compliance and adherence, ${ }^{37-39}$ whereas some studies found no association in this respect. ${ }^{40-45}$

Bastos-Barbosa et $\mathrm{a}^{46}$ emphasized the adverse impact of comorbidities on antihypertensive treatment. Cognitive impairment is listed as one of the many reasons for lack of compliance and medication adherence in elderly patients. Our study confirmed the adverse effect of cognitive impairment on the HBCS total scores and medication taking subscale scores. Similarly, a Medicaid study demonstrated that only $20 \%$ of hypertensive patients aged $>65$ years adhered to therapy. ${ }^{47}$ Additionally, age-related problems with memory might contribute to nonadherence and poor understanding of complex pharmacotherapy and mechanisms behind medication efficacy. ${ }^{48}$

Effective antihypertensive therapy undoubtedly lowers the risk of vascular dysfunctions. ${ }^{49}$ Hypertension that remains untreated for many years or is unsuccessfully treated for reasons such as poor compliance and adherence of the patient may lead to cognitive impairment. Active participation in the treatment (compliance and adherence) may prevent the development of complications and progressing decline in daily functioning. ${ }^{23}$

To sum up, it has to be pointed out that comprehensive understanding of the influence of all patients' behaviors in relation to their cognitive impairment on nonadherence is necessary for clinicians and caregivers to improve the quality of care. In addition, much more sufficient education for patients and their families is needed. Subjects with cognitive impairment may not be able to successfully understand, maintain or follow instructions, implying that interventions focusing on traditional strategies for patient education may fall down in this case. Above all, health care providers need to explore understanding and concerns regarding medications of patients with impaired cognition, which may result in reduction in intentional nonadherence. Educational strategies for indication, medication and adverse events, together with the observation of patients' tolerance of side effects, may show a significant improvement in this area. Moreover, a brief screening tool for identifying at-risk patients for effective monitoring and improving the assessment methods may play an important role in adherence interventions. It should be mentioned that electronic monitoring provides objective, more valid, and clinically valuable longitudinal data than other strategies such as self-reports and pill counts regarding a prospective observation of adherence. ${ }^{17,18,50}$

\section{Study limitations}

We are well aware of the potential limitations of this study. The most important of these stem from the fact that our study sample was recruited from a single center. We plan to extend our research on this subject and include more medical centers in the study.

\section{Conclusion}

Cognitive impairment was negatively associated with treatment compliance. Compliance and adherence levels were higher in patients with a higher educational level, while male sex adversely affected treatment adherence in elderly hypertensive patients. 


\section{Data sharing statement}

All coauthors have agreed to the submission and publication of this manuscript. The authors are able to provide a signed consent if required by the Journal Editor. The authors confirm that all data underlying the findings described in this manuscript are fully available to all interested researchers upon request.

\section{Acknowledgments}

There were no other contributors to the article than the authors. This article did not require to receive any specific grant from funding agencies in the public, commercial or not-for-profit sectors.

\section{Author contributions}

All authors of this manuscript meet the authorship criteria according to the latest guidelines of the International Committee of Medical Journal Editors (ICMJE), as well as all authors have seen and approved the manuscript being submitted and published.

\section{Disclosure}

The authors report no conflicts of interest in this work.

\section{References}

1. Ballesteros S, Mayas J, Reales JM. Cognitive function in normal aging and in older adults with mild cognitive impairment. Psicothema. 2013;25(1):18-24

2. Murman DL. The impact of age on cognition. Semin Hear. 2015;36(3): 111-121.

3. Ishizaki T, Yoshida H, Suzuki T, et al. Effects of cognitive function on functional decline among community-dwelling non-disabled older Japanese. Arch Gerontol Geriatr. 2006;42(1):47-58.

4. Johnston SC, O'Meara ES, Manolio TA, et al. Cognitive impairment and decline are associated with carotid artery disease in patients without clinically evident cerebrovascular disease. Ann Intern Med. 2004; 140(4):237-247.

5. Kilander L, Nyman H, Boberg M, Hansson L, Lithell H. Hypertension is related to cognitive impairment: a 20-year follow-up of 999 men. Hypertension. 1998;31(3):780-786.

6. Eguchi K, Kario K, Hoshide S, et al. Greater change of orthostatic blood pressure is related to silent cerebral infarct and cardiac overload in hypertensive subjects. Hypertens Res. 2004;27(4):235-241.

7. Vicario A, Del Sueldo M, Fernández RA, Enders J, Zilberman J, Cerezo GH. Cognition and vascular risk factors: an epidemiological study. Int J Hypertens. 2012;2012:783696.

8. Perrotta M, Lembo G, Carnevale D. Hypertension and dementia: epidemiological and experimental evidence revealing a detrimental relationship. Int J Mol Sci. 2016;17(3):347.

9. Tadic M, Cuspidi C, Hering D. Hypertension and cognitive dysfunction in elderly: blood pressure management for this global burden. BMC Cardiovasc Disord. 2016;16(1):208.

10. Iadecola C, Yaffe K, Biller J, et al. Impact of hypertension on cognitive function. Hypertension. 2016;68(6):e67-e94.

11. Hughes TM, Sink KM. Hypertension and its role in cognitive function: current evidence and challenges for the future. Am J Hypertens. 2016;29(2):149-157.
12. Elias MF, Wolf PA, D'Agostino RB, Cobb J, White LR. Untreated blood pressure level is inversely related to cognitive functioning: the Framingham Study. Am J Epidemiol. 1993;138(6):353-364.

13. Arlt S, Lindner R, Rösler A, von Renteln-Kruse W. Adherence to medication in patients with dementia: predictors and strategies for improvement. Drugs Aging. 2008;25(12):1033-1047.

14. Elliott RA, Goeman D, Beanland C, Koch S. Ability of older people with dementia or cognitive impairment to manage medication regimens: a narrative review. Curr Clin Pharmacol. 2015;10(3):213-221.

15. Stilley CS, Bender CM, Dunbar-Jacob J, Sereika S, Ryan CM. The impact of cognitive function on medication management: three studies. J Health Psychol. 2010;29(1):50-55.

16. Dolansky MA, Hawkins MA, Schaefer JT, et al. Association between poorer cognitive function and reduced objectively monitored medication adherence in patients with heart failure. Circ Heart Fail. 2016;9(12):e002475.

17. Smith D, Lovell J, Weller C, et al. A systematic review of medication non-adherence in persons with dementia or cognitive impairment. PLoS One. 2017;12(2):e0170651.

18. Campbell NL, Boustani MA, Skopelja EN, Gao S, Unverzagt FW, Murray MD. Medication adherence in older adults with cognitive impairment: a systematic evidence-based review. Am J Geriatr Pharmacother. 2012;10(3):165-177.

19. Austin J, Klein K, Mattek N, Kaye J. Variability in medication taking is associated with cognitive performance in nondemented older adults. Alzheimers Dement (Amst). 2017;6:210-213.

20. Jerant A, Chapman B, Duberstein P, Robbins J, Franks P. Personality and medication non-adherence among older adults enrolled in a six-year trial. Br J Health Psychol. 2011;16(pt 1):151-169.

21. Johnell K. Inappropriate drug use in people with cognitive impairment and dementia: a systematic review. Curr Clin Pharmacol. 2015;10(3): $178-184$.

22. Jin J, Sklar GE, Min Sen Oh V, Chuen Li S. Factors affecting therapeutic compliance: a review from the patient's perspective. Ther Clin Risk Manag. 2008;4(1):269-286.

23. Banegas JR, Guallar-Castillón P, Rodríguez-Artalejo F, Graciani A, López-García E, Ruilope LM. Association between awareness, treatment, and control of hypertension, and quality of life among older adults in Spain. Am J Hypertens. 2006;19(7):686-693.

24. Uchmanowicz I, Jankowska-Polańska B, Chudiak A, SzymańskaChabowska A, Mazur G. Psychometric evaluation of the Polish adaptation of the Hill-Bone Compliance to High Blood Pressure Therapy Scale. BMC Cardiovasc Disord. 2016;16:87.

25. Folstein MF, Folstein SE, McHugh PR. "Mini-mental state”. A practical method for grading the cognitive state of patients for the clinician. J Psychiatr Res. 1975;12(3):189-198.

26. Skoog I, Lernfelt B, Landahl S, et al. 15-year longitudinal study of blood pressure and dementia. Lancet. 1996;347(9009):1141-1145.

27. Tzourio C, Dufouil C, Ducimetière P, Alpérovitch A. Cognitive decline in individuals with high blood pressure: a longitudinal study in the elderly. EVA Study Group. Epidemiology of Vascular Aging. Neurology. 1999;53(9):1948-1952.

28. Launer LJ, Masaki K, Petrovitch H, Foley D, Havlik RJ. The association between midlife blood pressure levels and late-life cognitive function. The Honolulu-Asia Aging Study. JAMA. 1995;274(23):1846-1851.

29. Hanon O. Hypertension in the elderly and risk of dementia. Rev Prat. 2010;60(5):649-653.

30. Hanon O, Seux ML, Lenoir H, Latour F, Rigaud AS, Forette F. Cognitive functions and hypertension. Arch Mal Coeur Vaiss. 2005;98(2):133-139.

31. Ramli A, Ahmad NS, Paraidathathu T. Medication adherence among hypertensive patients of primary health clinics in Malaysia. Patient Prefer Adherence. 2012;6:613-622.

32. Osamor PE, Owumi BE. Factors associated with treatment compliance in hypertension in southwest Nigeria. J Health Popul Nutr. 2011; 29(6):619-628.

33. Familoni BO, Ogun SA, Aina AO. Knowledge and awareness of hypertension among patients with systemic hypertension. J Natl Med Assoc. 2004;96(5):620-624. 
34. Zaghloul SS, Goodfield MJD. Objective assessment of compliance with psoriasis treatment. Arch Dermatol. 2004;140(4):408-414.

35. Zdrojewski T, Solnica B, Cybulska B, et al. Prevalence of lipid abnormalities in Poland. The NATPOL 2011 survey. Kardiol Pol. 2016; 74(3):213-223.

36. Gokdemir G, Arı S, Köşlü A. Adherence to treatment in patients with psoriasis vulgaris: Turkish experience. J Eur Acad Dermatol Venereol. 2008;22(3):330-335.

37. Apter AJ, Reisine ST, Affleck G, Barrows E, ZuWallack RL. Adherence with twice-daily dosing of inhaled steroids. Socioeconomic and health-belief differences. Am J Respir Crit Care Med. 1998;157(6 pt 1): $1810-1817$.

38. Okuno J, Yanagi H, Tomura S. Is cognitive impairment a risk factor for poor compliance among Japanese elderly in the community? Eur J Clin Pharmacol. 2001;57(8):589-594.

39. Yavuz A, Tuncer M, Erdoğan O, et al. Is there any effect of compliance on clinical parameters of renal transplant recipients? Transplant Proc. 2004;36(1):120-121.

40. Norman SA, Marconi KM, Schezel GW, Schechter CF, Stolley PD. Beliefs, social normative influences, and compliance with antihypertensive medication. Am J Prev Med. 1985;1(3):10-17.

41. Horne R, Weinman J. Patients' beliefs about prescribed medicines and their role in adherence to treatment in chronic physical illness. J Psychosom Res. 1999;47(6):555-567.

42. Spikmans FJM, Brug J, Doven MMB, Kruizenga HM, Hofsteenge GH, van Bokhorst-van der Schueren MA. Why do diabetic patients not attend appointments with their dietitian? J Hum Nutr Diet. 2003;16(3): $151-158$.
43. Stilley CS, Sereika S, Muldoon MF, Ryan CM, Dunbar-Jacob J. Psychological and cognitive function: predictors of adherence with cholesterol lowering treatment. Ann Behav Med. 2004;27(2):117-124.

44. Kaona FA, Tuba M, Siziya S, Sikaona L. An assessment of factors contributing to treatment adherence and knowledge of TB transmission among patients on TB treatment. BMC Public Health. 2004;4:68.

45. Wai C-T, Wong M-L, Ng S, et al. Utility of the Health Belief Model in predicting compliance of screening in patients with chronic hepatitis B. Aliment Pharmacol Ther. 2005;21(10):1255-1262.

46. Bastos-Barbosa RG, Ferriolli E, Coelho EB, Moriguti JC, Nobre F, Lima NK. Association of frailty syndrome in the elderly with higher blood pressure and other cardiovascular risk factors. Am J Hypertens. 2012;25(11):1156-1161.

47. Monane M, Bohn RL, Gurwitz JH, Glynn RJ, Levin R, Avorn J. Compliance with antihypertensive therapy among elderly Medicaid enrollees: the roles of age, gender, and race. Am J Public Health. 1996; 86(12): 1805-1808

48. Vrijens B, Vincze G, Kristanto P, Urquhart J, Burnier M. Adherence to prescribed antihypertensive drug treatments: longitudinal study of electronically compiled dosing histories. BMJ. 2008;336(7653): $1114-1117$.

49. Głuszek J, Jankowska K. Dementia caused by hypertension. Heart Blood Vessels Dis. 2005;2(3):125-130.

50. Stilley CS, Bender CM, Dunbar-Jacob J, Sereika S, Ryan CM. The impact of cognitive function on medication management: three studies. Health Psychol. 2010;29(1):50-55.
Clinical Interventions in Aging

\section{Publish your work in this journal}

Clinical Interventions in Aging is an international, peer-reviewed journal focusing on evidence-based reports on the value or lack thereof of treatments intended to prevent or delay the onset of maladaptive correlates of aging in human beings. This journal is indexed on PubMed Central, MedLine,

\section{Dovepress}

CAS, Scopus and the Elsevier Bibliographic databases. The manuscript management system is completely online and includes a very quick and fair peer-review system, which is all easy to use. Visit http://www.dovepress. com/testimonials.php to read real quotes from published authors. 